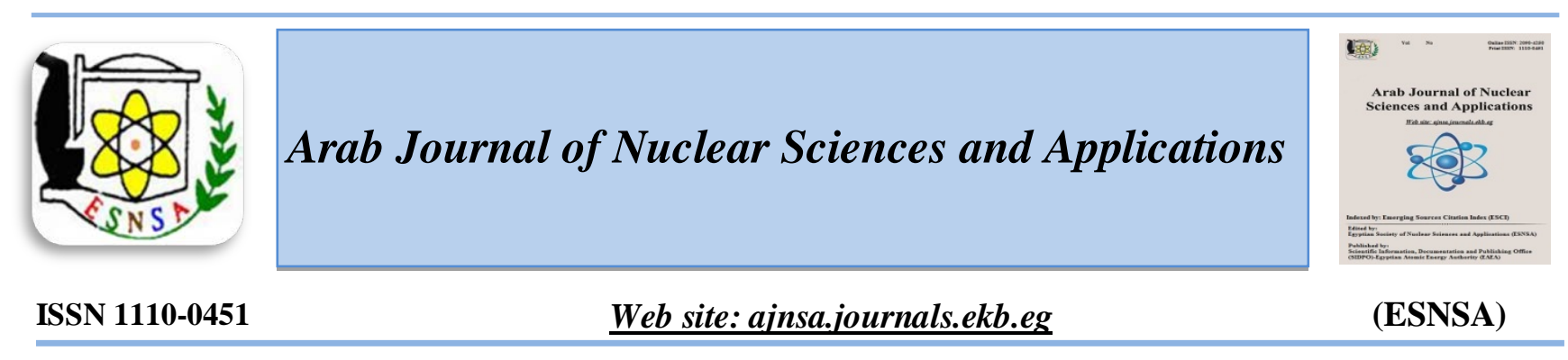

\title{
Design of a Portable Shield for Neutron Sources Using MCNP Computer Code
}

\author{
Randa M. M. Mahmoud \\ Radiation Protection department, Nuclear and Radiological Regulatory Authority, Cairo, Egypt
}

\begin{abstract}
Received $13^{\text {rd }}$ Dec. 2017 In this work, a design of a portable shield for neutron sources is proposed using MCNP5 code for Accepted $3^{\text {rd }}$ July 2018 neutron and gamma total dose rate calculation. The shield is composed of three layers, as follows: lead layer for gamma attenuation, PMMA (Poly-methyl methacrylate) layer for fast neutron thermalization and a layer of $\mathrm{B}_{2} \mathrm{O}_{3}$ for thermal neutron absorption. The shield is contained in a stainless steel container of $0.5 \mathrm{~mm}$ thick. The source design verification has been carried out by experimental measurements at different source- to detector distance. The energy spectrum of an ${ }^{241} \mathrm{Am}$-Be source is considered in order to study the neutron moderation due to successive elastic scattering with PMMA layer. The neutron and photon total dose rates have been calculated at the surface and one meter from the shield. The results of MCNP5 model are compared with the international transport regulation to ensure the suitability of neutron shield proposed design. The results show that the proposed design of the portable shield satisfies the dose rate limits and can be used for controlling external radiation level during neutron sources transportation, ensuring the safety transport conditions and protection of radiation workers in different applications.
\end{abstract}

Keywords: Portable Shield Design / Neutron Sources / MCNP Code.

\section{Introduction}

Neutron sources are used in different applications such as physics, engineering, medicine, petroleum exploration, biology, chemistry and nuclear power. Exposure to neutrons can be hazardous, considering the interaction of neutrons with body molecules [1]. There are three common types of neutron sources, namely, neutrons produced by the interaction of high speed ${ }^{2} \mathrm{H}$ ions with ${ }^{3} \mathrm{H}$ atoms. The second type is arises from spontaneous fission of ${ }^{252} \mathrm{Cf}$; and the last one is the Am- Be source with americium $\left({ }^{241} \mathrm{Am}\right)$ as an alpha emitter, and beryllium (Be), as a target for neutron production [2].

For most applications, using neutron sources is not required in separated shielded places, but it needs an extra appropriate portable shield to ensure workers protection against neutron radiation during conducting their work. Main radiological characteristics of the neutron shielding materials reside in the ability to slowing down and moderate the fast neutron by low-Z material and the ability to absorb thermal neutron by high cross-section materials. As a common example, a cheap and relatively effective shielding choice is light hydrogen, in the form of ordinary water, paraffin or polyethylene, for instance. At the very least, several inches of any of these substances will moderate the initial spectrum from neutron sources such as Am-Be to a large degree, and make the more "ravenous" neutron absorbers such as borax (boron, thermal cross section $~ 755$ barns) or cadmium (2450 barns, but chemically toxic) far more effective [3]. ${ }^{241} \mathrm{Am}$-Be neutron source is widely used for different applications. This work aims to propose a design of a portable shield for ${ }^{241} \mathrm{Am}$-Be neutron sources in accordance with the international transport regulations to control the radiation external level.

Corresponding author: randam76@yahoo.com

DOI: $10.21608 /$ ajnsa.2018.2256.1021

(C) Scientific Information, Documentation and Publishing Office (SIDPO)-EAEA 


\section{Regulation for safety transport}

The proposed portable shield is designed to protect workers against radiation during the transport of an ${ }^{241} \mathrm{Am}-\mathrm{Be}$ source in accordance with the international transport regulations and also to comply with IAEA Safety Standards Series No. SSR-6 [4]. The packages are categorized into four categories depending on the transport index and the dose rate at the package surface. The proposed shield is designed for Yellow II category (low radiation level [5]) and Yellow III category (high radiation level), while the surface dose rate ranged from $0.005 \mu \mathrm{Sv} / \mathrm{h}$ to $0.5 \mu \mathrm{Sv} / \mathrm{h}$, and $0.5 \mu \mathrm{Sv} / \mathrm{h}$ to 2 $\mu \mathrm{Sv} / \mathrm{h}$, respectively.

\section{Background information on americium-beryllium} source

The source used in this study is ${ }^{241} \mathrm{Am}-\mathrm{Be}$ characterized by an activity of $5 \mathrm{Ci}$ (in 1977), the neutron emissions of $1.1 \times 10^{7} \mathrm{n} / \mathrm{sec}$, and of a halflife of 432.2 years. The Amersham catalog of $1977 / 8$ [6] provides the information on the ${ }^{241} \mathrm{Am}$ Be source composition which is a compacted mixture of americium oxide with beryllium metal, double encapsulated in a welded stainless steel capsule, as can be seen in Figure(1).

The ${ }^{241} \mathrm{Am}$-Be neutron source has an isotropic emission with energies range from $\sim 2 \mathrm{MeV}$ to 10 $\mathrm{MeV}$ and indicates that there are approximately $23 \%$ of neutrons below $1 \mathrm{MeV}$ with average energy 4.4 MeV[6] as shown in Figure(2).

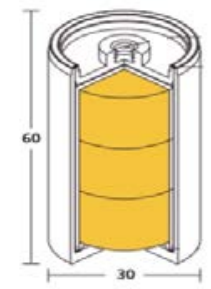

Figure (1): The source is double encapsulated in

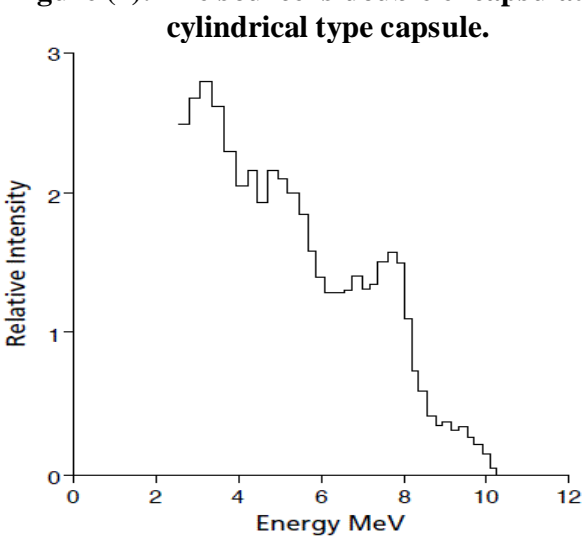

Figure (2): Am-Be neutron spectrum
Monte Carlo simulation code

MCNP5 (Monte Carlo N-P particle, version5) is a general purpose radiation particle transport code for modeling the interaction of radiation with material. It also allows the simulation of physical events occurring during detection and registration of N-P particles [7].

The MCNP5 model is used to simulate a portable shield design for neutron sources which can be used in different applications, in order to assure the safety transport and protection of workers against radiation.

\section{Methods and calculations}

The development of the portable shield design for neutron source was performed in three steps, namely:

1. A neutron source structure design is simulated by using the MCNP5 model and the source design verification is carried out by practical measurements;

2. Some materials were selected for shield design and MCNP5 is used to calculate the dose rate and estimate the suitable material thickness ; and

3. Different arrangements of the selected material were simulated in order to obtain an appropriate estimation of the shield design.

\section{Neutron source simulation using MCNP5 model}

In order to develop a portable shield design for neutron sources, a neutron source structure is simulated by using MCNP5, with certain dimensions according to the Amersham catalog [6]. Figure(3) shows the model geometry for neutron source structure in air, surrounded by $1 \mathrm{~cm}$ holder made of Poly-methyl methacrylate (PMMA). The dose rate was calculated using MCNP5 at different distance from the source center. The flux was calculated using the point detector technique and F5 tally. The neutron flux to dose conversion factor (ANSI/ANS-6.1.1-1977) and $\gamma$-photon flux to dose conversion factor (ICRP-21)[8] are used to calculate the dose rate using dose energy card DEn and dose function card DFn. A number of $10^{6}$ neutrons and $\gamma$-photons were used to simulate the transport of neutrons, $\gamma$-photons and accumulate neutrons, $\gamma$ tallies.

The source design verification was carried out by the experimental measurements of the dose rate at different distances from the source center using calibrated neutron detector of model Nuclear 
Enyerprises NM2, which has a wide measuring energy range, at the National Institute of Standards (NIS).

\section{Selection of shielding materials compositions and} thickness

In this work, the calculations consider three types of shielding materials: Poly-methyl methacrylate (PMMA) as a hydrogen-rich material, boron oxide as a neutron absorber and lead for gamma radiation, respectively.

PMMA, known by the trade names, as Perspex, is a transparent lightweight material thermoplastic which does not shatter on rupture, but only highly scratched. It is impact resistant, with chemical formula $\left(\mathrm{C}_{5} \mathrm{H}_{8} \mathrm{O}_{2}\right)$ n. PMMA is often preferred because of its moderate properties, easy handling and processing, and low cost. PMMA also is one of the polymers that is most resistant to direct sunshine exposure with a melting point of $\approx 130^{\circ} \mathrm{C}$ [9], which make it more suitable for transport in desert roads than wax and paraffin with melting points of $\approx 50 \sim 70{ }^{\circ} \mathrm{C}$.
The objective of this step is to determine the required thickness of the selected materials in order to reduce the dose rate to the accepted values for the shield design. The calculations consider three cylindrical layers for the selected materials, namely: PMMA (as shown in Figure(4)), $\mathrm{B}_{2} \mathrm{O}_{3}$ and $\mathrm{Pb}$, respectively. The shield material layers should sufficient to satisfy the prescribed dose rate for transportation requirement. Figure(5) shows the model geometry for the cylindrical shield layers structure which is composed of the three selected materials mentioned above.

\section{Optimization of shielding materials arrangement} In order to decrease the weight of the designed shield, the calculation is performed for two suggested different model geometries, namely: MG.A and MG.B, as shown in Figure(6.a) and Figure(6.b) respectively. The $\mathrm{Pb}$ layer is represented in the model geometry arrangement MG.A in the outer shield, and in the model arrangement MG.B in the inner shield, respectively.

In the thermal energy region, boron oxide $\left(\mathrm{B}_{2} \mathrm{O}_{3}\right)$ is used as a neutron-capturing agent due to its high absorption cross section [10].

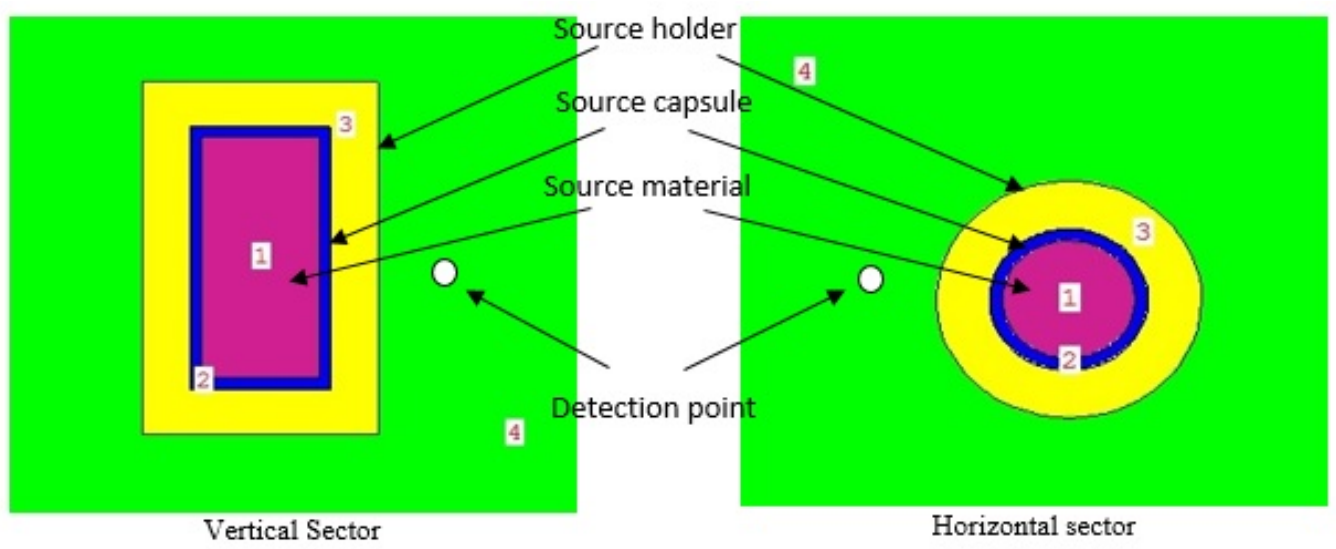

Figure (3): The model geometry for neutron source structure

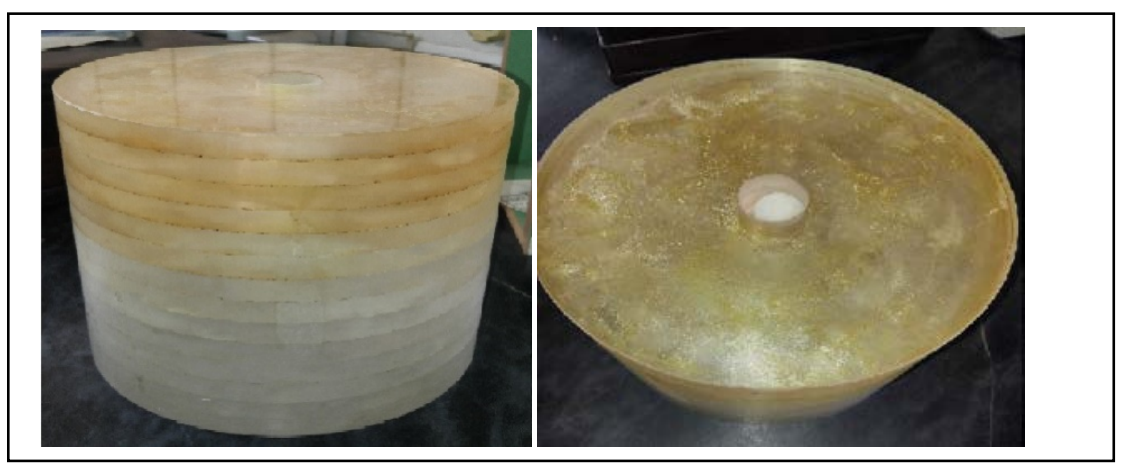

Figure (4): PMMA cylindrical shield layer for neutron moderation 


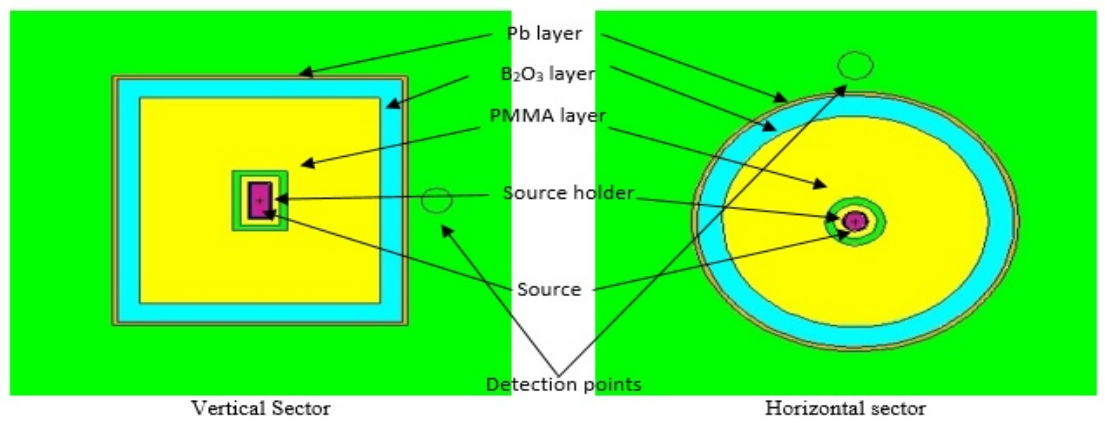

Figure(5): The model geometry for cylindrical shield layers structure

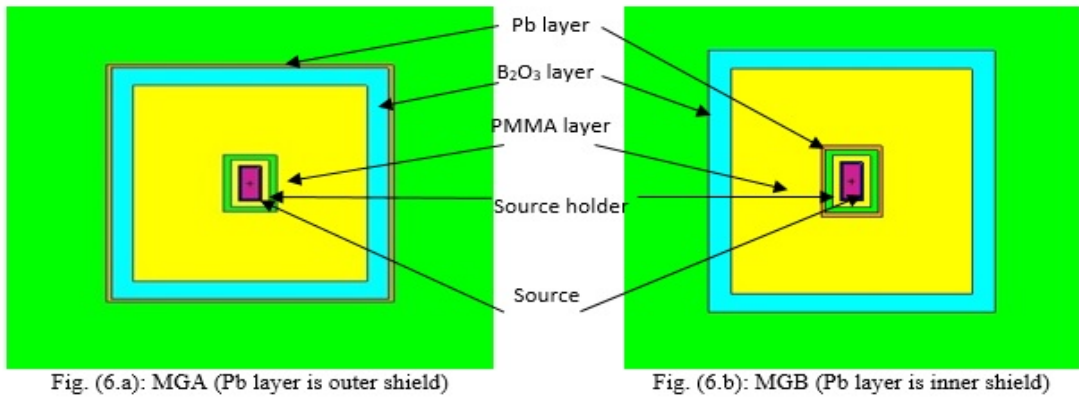

Figure (6): The model geometry layers arrangement for the shield composition.

\section{Neutron source simulation}

The ${ }^{241} \mathrm{Am}$-Be source design is simulated using MCNP5 and the dose rate was calculated at different distances from the source-center, in the air. The verification of the source design is carried out by comparing the MCNP5 calculated doses with the experimentally measured ones. Table (1) illustrates the comparison between the calculated and the measured dose rates at different source -todetector distances. The combined uncertainty in neutron dose measurement was considering some parameters such as the uncertainty in repeatability, position, calibration factor of the instruments used, stability, scattered, and resolution and extracted a value of $2.18 \%$.The expanded uncertainty was obtained from the combined uncertainty calculated above with coverage factor of 2 and confidence level of $95 \%$ as reported in Table (1) [11].

Figure (7) illustrates the comparison between the calculated and the measured dose rates at different distances source -to-detector. The results show that there was a good agreement between calculated and measured dose rate, which indicates a good verification of source design.

\section{Shielding materials thickness}

The data of the attenuated neutron flux by different thickness of PMMA shield as calculated by MCNP5 and the corresponding dose rate at the shield surface are illustrated in Figure(8). The results show that dose rate decreases exponentially with PMMA shield thickness. This may be attributed to the high neutrons moderation by hydrogen and other PMMA light elements content by elastic scattering. It is also observed that $14 \mathrm{~cm}$ of PMMA layer is sufficient to reduce the energy of Am-Be to thermal component.

The neutron-capture with B2O3 layer thickness is simulated by MCNP5 and the surface dose rate for different B2O3 layer thickness is calculated and illustrated in Fig.(9). The optimized thickness for $\mathrm{B} 2 \mathrm{O} 3$ is $3 \mathrm{~cm}$. The gamma attenuation for different lead shield thickness is calculated by MCNP5 and illustrated in Figure(10). The optimized thickness for $\mathrm{Pb}$ layer is $0.9 \mathrm{~cm}$.

\section{Shielding materials arrangement optimization}

The shield performance was evaluated to confirm whether the thickness optimization is still effective with the shield weight or not. The dose rate was calculated using MCNP5 for the two suggested model geometries MG.A and MG.B, at different $\mathrm{Pb}$ layer thickness. The results illustrated in Figs. $(11,13$ and 15) indicate that the dose rate decreases gradually with increasing the $\mathrm{Pb}$ shield thickness. Figs. (12, 14 and 16) show an inverse relationship between the surface dose rate and weight of the shield, as mentioned by Murthy et.al, [12]. 
Table (1): A comparison between the calculated and measured dose rates at different source-to-detector distances

\begin{tabular}{|c|c|c|c|c|c|}
\hline $\begin{array}{c}\text { Source -to- } \\
\text { detector } \\
\text { distance }(\mathrm{cm})\end{array}$ & $\begin{array}{c}\text { MCNP } \\
\text { Calculated } \\
\text { Dose }(\mathrm{mSv} / \mathrm{h})\end{array}$ & Error \% & $\begin{array}{c}\text { Measured } \\
\text { dose } \\
(\mathrm{mSv} / \mathrm{h})\end{array}$ & $\begin{array}{c}\text { Expanded } \\
\text { uncertaint } \\
\mathrm{y} \%\end{array}$ & $\begin{array}{c}\text { Estimate } \\
\text { d errors } \\
\pm \%\end{array}$ \\
\hline 13 & 6.70427 & 0.001 & 6.06 & 0.045 & 0.096 \\
\hline 15 & 3.50083 & 0.001 & 4.47 & 0.045 & 0.277 \\
\hline 20 & 2.83653 & 0.001 & 2.3 & 0.045 & 0.189 \\
\hline 35 & 0.92814 & 0.001 & 0.8348 & 0.045 & 0.101 \\
\hline 45 & 0.561984 & 0.001 & 0.4963 & 0.045 & 0.117 \\
\hline 90 & 0.140906 & 0.001 & 0.127 & 0.045 & 0.099 \\
\hline 160 & 0.0445848 & 0.001 & 0.047 & 0.045 & 0.054 \\
\hline 180 & 0.0352107 & 0.001 & 0.0405 & 0.045 & 0.150 \\
\hline 210 & 0.0258693 & 0.0018 & 0.03043 & 0.045 & 0.176 \\
\hline
\end{tabular}

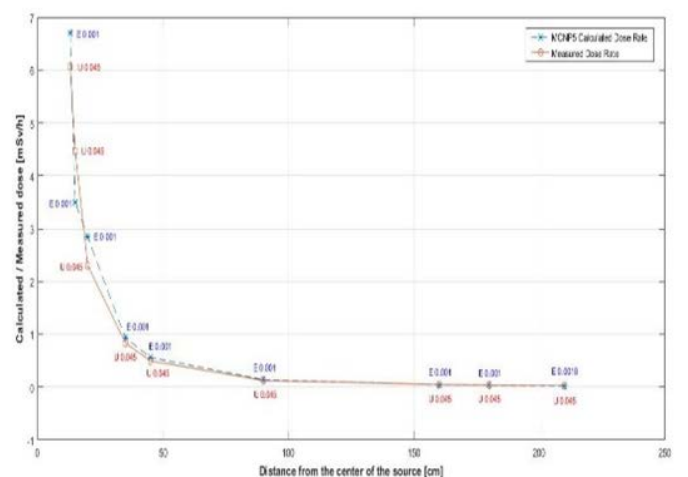

Figure(7): A comparison between the calculated and the measured dose rates at different distance from the source

In order to assess the surface dose rate in the light of the dose limits by the international transport regulations [4], the results show the following:

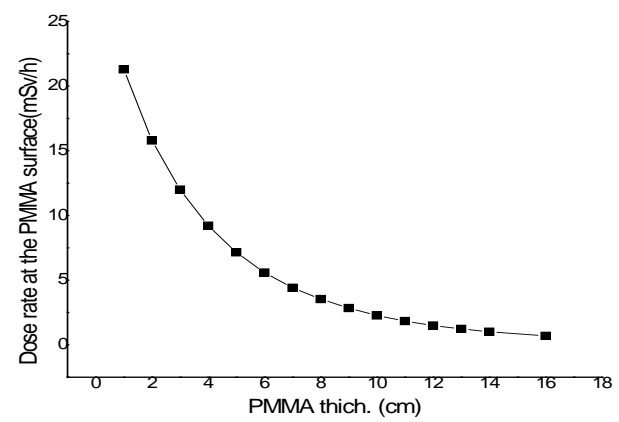

Figure (8): Evolution of the calculated surface dose rate at the PMMA shield layer with shield thickness

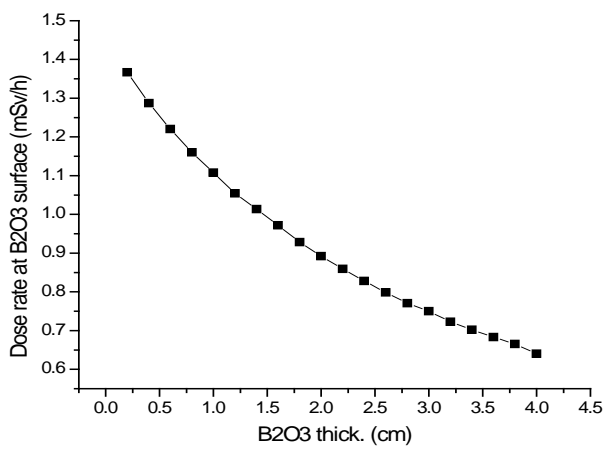

Figure(9): Evolution of the calculated surface dose rate at the $\mathrm{B}_{2} \mathrm{O}_{3}$ shield layer with shield thickness

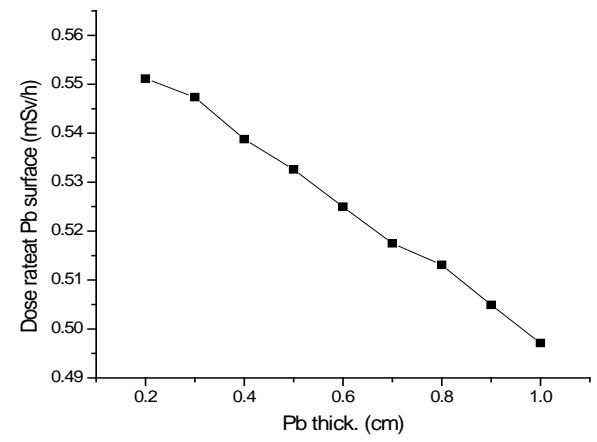

Figure (10): Evolution of the calculated surface dose rate at the Pb shield layer with shield thickness

For low radiation levels (dose limit $=0.5 \mathrm{mSv} / \mathrm{h}$ ): Figure(11) shows a comparison between the surface dose rate and weight for the two model geometries, MG.A and MG.B, respectively. The results indicate that the dose rate decreases gradually with increasing the shield thickness. The inverse relationship between the surface dose rate 
and weight of the shield, as mentioned by Murthy et.al, [12] is also observed.

Figures (11 and 12) indicate that for the tested source, the most effective shield design to achieve the target dose rate of $0.5 \mathrm{mSv} / \mathrm{h}$ for low radiation level and less weight $(109.3 \mathrm{~kg})$ is the arrangement MG.B ( $\mathrm{Pb}$ layer is inner shield), while thickness of $\mathrm{Pb}$, PMMA and B2O3 layers are 0.8, 14, and 3 $\mathrm{cm}$, respectively.

This may be attributed to the fact that the lead layer in the inner shield is desirable for inelastic neutron scattering to effectively bring the neutron energy down to lower energy and less dose rate in addition to the attenuation of associated gamma, which is in agreement with Jeon DongKim et, al.[13].

For the low radiation levels, the dose rate at $1 \mathrm{~m}$ from the shield is founded to be $5.5 \mu \mathrm{Sv} / \mathrm{h}$, which means that the transport index for the shield package is not larger than 0.5 .

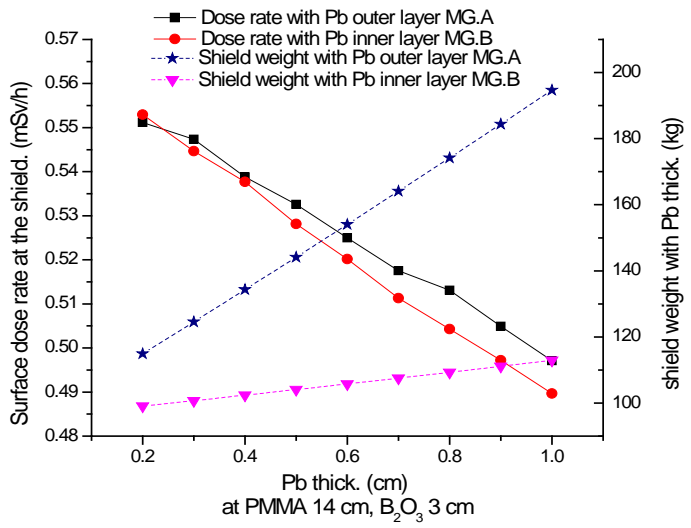

Figure (11): A comparison between the surface dose rate and the weight of the two model geometries MG.A and MG.B design with $\mathrm{Pb}$ shield thickness for low radiation levels

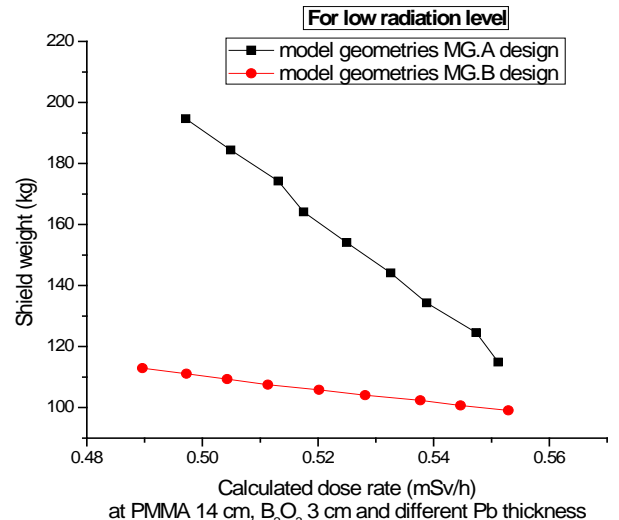

Figure(12): A comparison between the shield weight with calculated surface dose rate of the two model geometries MG.A and MG.B design for low radiation levels.

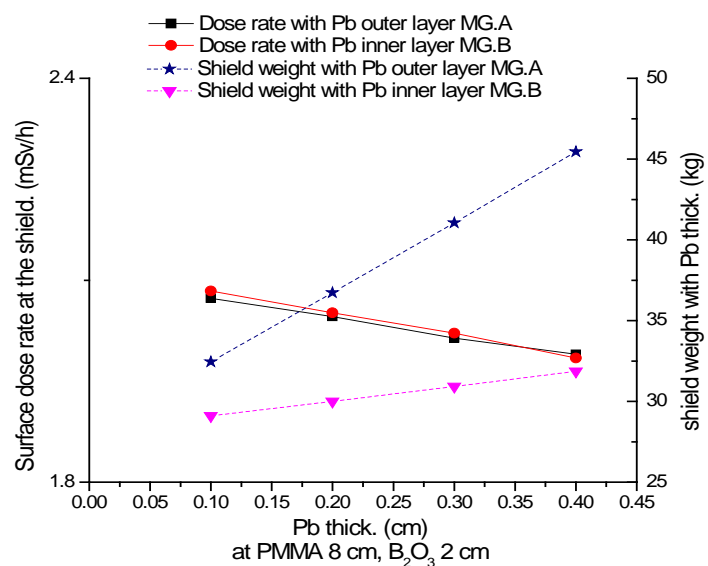

Figure (13): A comparison between the surface dose rate and the weight of the two model geometries MG.A and MG.B design with $\mathrm{Pb}$ shield thickness for high radiation levels

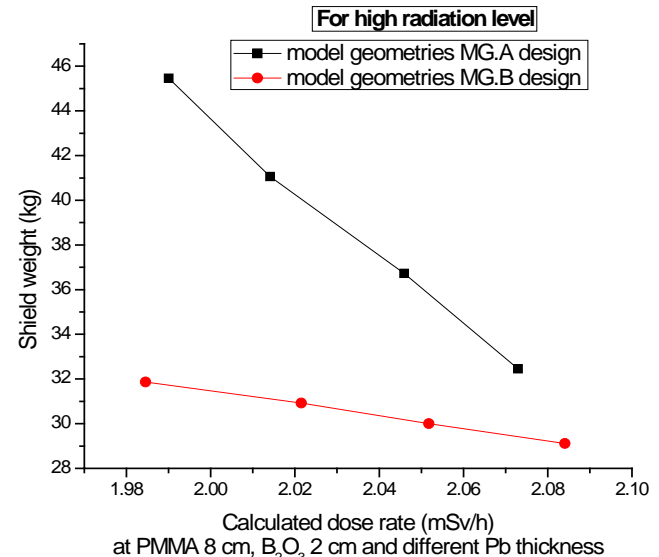

Figure (14): A comparison between the shield weight with the calculated surface dose rate of the two model geometries MG.A and MG.B design for high radiation levels

For high radiation levels (dose limit $=\mathbf{2 . 0}$ $\mathrm{mSv} / \mathrm{h})$ :

Figures (13 and 14) show a comparison between the surface dose rate and the weight for the two model geometries, MG.A and MG.B, respectively. The results analysis indicates that for the tested source, the most effective shield design to achieve the required dose rate of $2 \mathrm{mSv} / \mathrm{h}$ for high radiation level is MG.A arrangement ( $\mathrm{Pb}$ layer is the outer shield), but with a higher weight (41.058 $\mathrm{kg}$ ), while thickness of $\mathrm{Pb}, \mathrm{PMMA}$ and $\mathrm{B}_{2} \mathrm{O}_{3}$ layers are $0.3,8$, and $2 \mathrm{~cm}$, respectively.For the high radiation levels, the dose, at $1 \mathrm{~m}$ from the designed shield, is found to be $40.4 \mu \mathrm{Sv} / \mathrm{h}$.

MCNP5 simulations for the shield materials contained in a stainless steel container of $0.05 \mathrm{~mm}$ thickness for the considered arrangements MG.A ( $\mathrm{Pb}$ layer is inner shield) and MG.B (Pb layer is 
outer shield) are shown in Figs. (15 and 16).The results show that for the tested source, the most effective combination of the shield materials in the stainless steel container $(0.05 \mathrm{~mm}$ thickness $)$ assuring for the high radiation levels a surface dose rate less than $2 \mathrm{mSv} / \mathrm{h}$ with a lower weight (32.456 $\mathrm{kg}$ ) is given by MG.B (Pb layer is inner shield) arrangement.

This may be due to the effect of stainless steel and its attenuation for gamma ray resulted from the interaction between a thermal neutron and boron10 , as mentioned by Jumpee et al. [10].

The calculated dose at $1 \mathrm{~m}$ from this shield is equal to $40 \mu \mathrm{Sv} / \mathrm{h}$, which means that the suggested design is more effective with minimal weight.

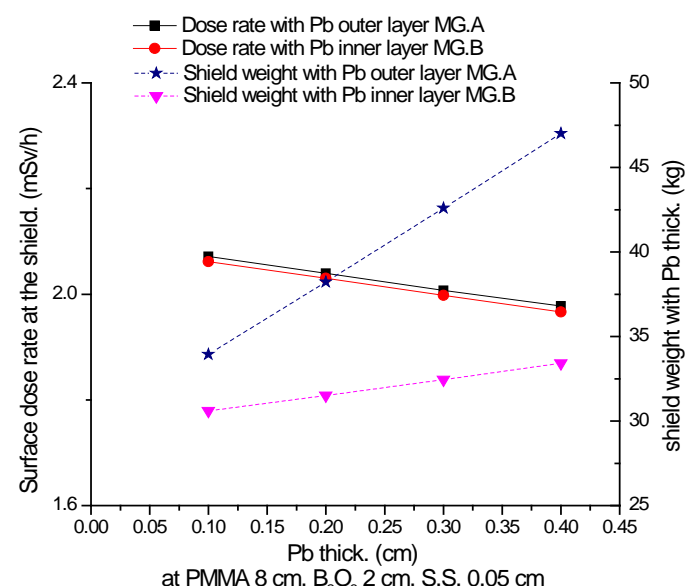

Figure(15): A comparison between the surface dose rate and the weight of the two model geometries MG.A and MG.B design with $\mathrm{Pb}$ shield thickness for high radiation levels (the stainless still container is also considered)

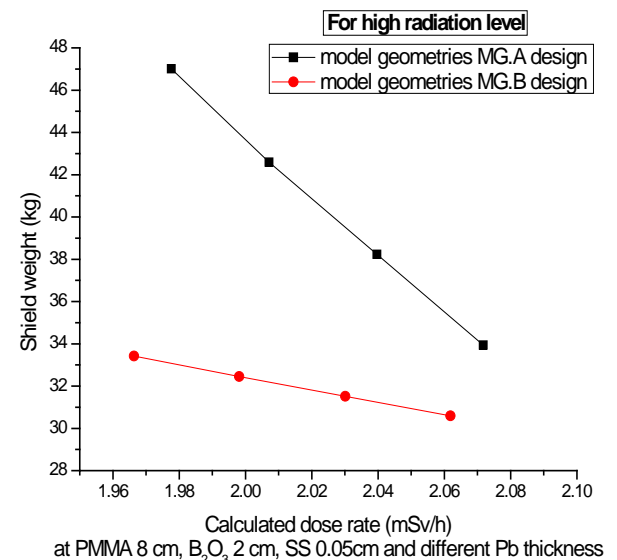

Figure (16): A comparison between the surface dose rate and the weight of the two model geometries MG.A and MG.B design with $\mathrm{Pb}$ shield thickness for high radiation levels (the stainless still container is also considered)

\section{Conclusion}

The results indicate that the selected materials can be used with different arrangements to control radiation levels with high shielding performances. Also the raw materials used for the shield design are suitable due to their cost, and physical and thermal properties.

The proposed shield design simulation results indicate that the use of this specific designed shield may control the external radiation level during neutron transport at:

-low radiation levels to obtain a surface dose less than $0.5 \mathrm{mSv} / \mathrm{h}$; with total mass of $109.3 \mathrm{~kg}$;

-high radiation levels to obtain a surface dose less than $2 \mathrm{mSv} / \mathrm{h}$; with total mass of $32.456 \mathrm{~kg}$; in order to comply with international requirements for transportation.

The proposed neutron sources shield design can ensure the safety of source transportation and the protection of workers against radiation during performing their work.

\section{Acknowledgment}

The author would like to express her deep thanks to Prof. Dr. Moustafa Aziz, Prof. Dr. Ahmed ElSersy and Prof. Dr. Mohamed Reda Ezz El-Din for their support and for fruitful discussion and advice to improve this work.

\section{Refernces}

1-Kenneth, S.J. and Faw, R. Radiation Shielding (Illinois: American Nuclear Society) (2000).

2-Shue, S.L., Faw, R.E., Shulis, J.k. Thermal-neutron intensities in soils irradiated by fast neutrons from point sources. Chemical Geology, 14, 447-61 (1998).

3-University of Guelph A Guide to Nuclear Radiation Shielding, Environmental Health and Safety (2005).

4-IAEA Safety Standards Series No. SSR-6, "Regulations for the Safe Transport of Radioactive Materials”, Vienna (2012).

5-U.S Department of Health \& Human Services, "Understanding Shipping Labels and Placards for Radioactive

Materials”.https://www.remm.nlm.gov/transportation hazard id.htm

6-Amersham, The Radiochemical Center Technical Bulletin 77/8, "Sources; Americium-Beryllium" (1977).

7-X-5 Monte Carlo Team, MCNP - A General Monte Carlo N-Particle Transport Code, Version 5.Los Alamos National Laboratory (2003).

8-Pelowitz D. B., “MCNP5TM usere's Manual” Los Alamos National Laboratory (2005). 
9-Milena Koleva, Technical University of Gabrovo CAE DS - Injection Moulding Materials.

10- C. Jumpee and D. Wongsawaeng1) Innovative neutron shielding materials composed of natural rubber-styrene butadiene rubber blends, boron oxide and iron(III) oxide, Journal of Physics: Conference Series 611) 012019 (2015).

11- A. R. El-Sersy, S. A. Eman, M. Ezzat and R.A. Ali The use of a new shielding material in construction of neutron irradiation facility for calibration purposes and dosimetric applications. Egyptian journal of biophysics. Vol. 11(1) (2015).

12- M. S. S. Murthy, J. S. Bisht, A. N. Nandakumar, K. C. Upadhyay, S. R. K. Iyer\&V. G. R. Subramanian, "Is There a Need for Reducing the Limit on Surface Dose Rates of Packages During Transport of Radioactive Material?” (2013) International Journal of Radioactive Materials Transport. Volume 6, - Issue 4 p.p. 235-238 (1995).

13- Jeong Dong Kim, SangjoonAhn, Yong Deok Lee, and Chang Je Park; "Design Optimization of Radiation of Shielding Structure for Lead Slowingdown Spectrometer System” Nucl. Eng. Technol. 47 pp. 380 -387 (2015). 